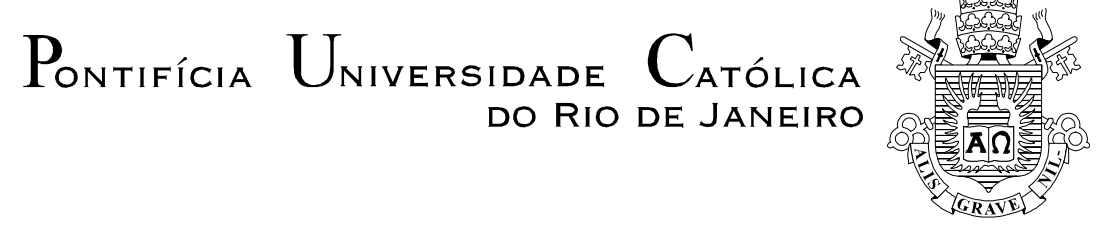

Maria Cristina Chaves de Carvalho

\title{
"Aqui o mar acaba e a terra principia": o lugar que se revela em A Jangada de Pedra
}

Dissertação de Mestrado

Dissertação apresentada como requisito parcial para obtenção do grau de Mestre pelo programa de Pós-Graduação em Letras do Departamento de Letras do Centro de Teologia e Ciências Humanas da PUC-Rio. Aprovada pela Comissão Examinadora adiante relacionada.

Orientadora: Profa. Dra. Cleonice Berardinelli

Rio de Janeiro

Março de 2006 


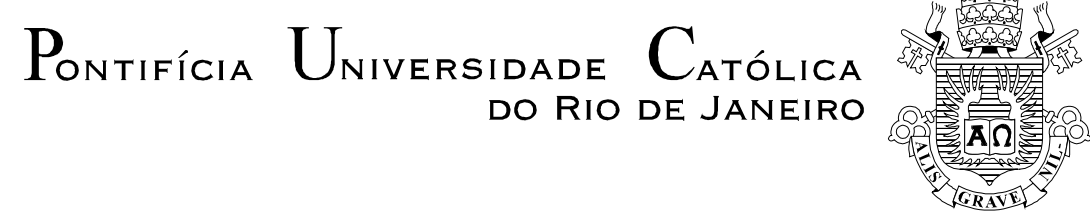

\section{Maria Cristina Chaves de Carvalho}

\section{"Aqui o mar acaba e a terra principia": o lugar que se revela em A Jangada de Pedra}

Dissertação apresentada como requisito parcial para obtenção do grau de Mestre pelo programa de Pós-Graduação em Letras do Departamento de Letras do Centro de Teologia e Ciências Humanas da PUC-Rio. Aprovada pela Comissão Examinadora abaixo assinada.

Profa. Dra.Cleonice Berardinelli

Orientadora

Departamento de Letras - PUC-Rio

Prof. Dra. Teresa Cristina Cerdeira Departamento de Letras - UFRJ

Prof. Dr. Alexandre Montaury Departamento de Letras - PUC-Rio

Prof. Dr. Paulo Fernando Carneiro de Andrade

Coordenador Setorial do Centro de Teologia e Ciências Humanas

Rio de Janeiro, 31 de março de 2006. 
Todos os direitos reservados. É proibida a reprodução total ou parcial do trabalho sem autorização da universidade, da autora e da orientadora.

\section{Maria Cristina Chaves de Carvalho}

Graduou-se em Letras (Português-Literaturas bacharelado e licenciatura) na Universidade Federal do Rio de Janeiro em 1989. Cursou Pós-Graduação Lato Sensu em Literatura Portuguesa na Universidade Federal do Rio de Janeiro em 2000.

Ficha Catalográfica

Carvalho, Maria Cristina Chaves de

"Aqui o mar acaba e a terra principia": o lugar que se revela em A Jangada de Pedra / Maria Cristina Chaves de Carvalho ; orientadora: Cleonice Berardinelli. - Rio de Janeiro: PUC, Departamento de Letras, 2006.

$73 \mathrm{f.} ; 30 \mathrm{~cm}$

Dissertação (mestrado) - Pontifícia Universidade Católica do Rio de Janeiro, Departamento de Letras.

Inclui referências bibliográficas.

1. Letras - Teses. 2. Saramago, José. 3. Viagem. 4. Identidade. 5. Memória. 6. Ficção . 7. História. I. Berardinelli, Cleonice. II. Pontifícia Universidade Católica do Rio de Janeiro. Departamento de Letras. III. Título. 


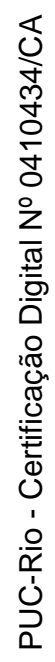

Para Alberto, "música em si mesmo", e para Rafael, "poesia sem par". 


\section{Agradecimentos}

À orientadora e amiga Cleonice Berardinelli, a gratidão por estar sempre "ao alcance da [minha] voz", por sua orientação e pelo seu cuidado.

À Alberto, por compartilhar a mesma viagem desde a estação Cais-de-Sodré.

Em memória de Maria da Gloria e Florindo, meus pais, aos quais agradeço e admiro pela dedicação à minha educação e principalmente por seu amor.

Às irmãs Isabel, Flora e Fátima, e ao irmão Luís Carlos, pela amizade e pelo apoio incondicional.

À Izabel, avó do Rafael, por sua presença amiga e afetuosa.

Ao amigo Julio Giannini, pela cumplicidade nas diversas jornadas.

À Alessandra e à Helenice, caminhantes e companheiras neste percurso.

Aos professores que participaram da banca exaninadora, pela presença relevante nesta etapa final.

Ao CNPq e à PUC-Rio pelo auxílio financeiro concedido.

A todos os funcionários - em especial, à Chiquinha - e professores e do Departamento de Letras da PUC-Rio, pelos ensinamentos e por sua ajuda.

Aos professores da UFRJ, por minha formação e pelo estímulo ao estudo da Literatura Portuguesa.

A todos os amigos e familiares que colaboraram para a realização deste trabalho. 


\section{Resumo}

CARVALHO, Maria Cristina Chaves de; BERARDINELLI, Cleonice. "Aqui o mar acaba e a terra principia": o lugar que se revela em A Jangada de Pedra. Rio de Janeiro, 2006. 73p. Dissertação de Mestrado Departamento de Letras, Pontifícia Universidade Católica do Rio de Janeiro.

Esta dissertação abarca uma leitura analítica do romance A Jangada de Pedra, com o intuito de penetrar na estética de uma ficção que, valendo-se da tradição de navegadores dos povos ibéricos, cria uma viagem mágica, em que é a própria terra que erra por sobre os mares: navegante a terra, caminhantes os seus heróis. Neste espaço utópico, reverdece a esperança de um futuro imprevisível. Ao promover um diálogo entre a ficção e a história, o autor apresenta um projeto ideológico, contendo suas inquietações em relação à cultura ibérica e ao contexto sócio-político da época, relativas à aceitação ou rejeição do ingresso da Península na União Européia. Neste cantar épico, José Saramago busca premiar, numa ilha imaginária, heróis anônimos - personagens sensíveis que, vogando no Oceano Atlântico, encontram o amor, possível mediante o conhecimento do próprio corpo e do espaço ibérico.

\section{Palavras-chave}

José Saramago; viagem; identidade; memória; ficção; história. 


\section{Abstract}

CARVALHO, Maria Cristina Chaves de: BERARDINELLI, Cleonice (Advisor). "Aqui o mar acaba e a terra principia": the place announces itself in A Jangada de Pedra. Rio de Janeiro, 2006. 73p. MSc. Dissertation - Departamento de Letras, Pontifícia Universidade Católica do Rio de Janeiro.

In the present thesis, an analytic reading of the novel A Jangada de Pedra is included so as to provide a deep study on the aesthetics of a fictional story which, regarding the tradition of Iberian navigators creates a magic voyage in which the land itself wanders on the seas: a land which floats with its walking heroes. In this utopian space, the hope on this unpredictable future is renewed. Promoting a dialogue between fiction and history, the author presents an ideological project, including the uneasiness the Iberian culture and the political and social context from that age bring him, according to the approval or the refusal of the Peninsula in the European Union. José Saramago threw himself into this epic mood in order to honour, in an imaginary island, anonymous heroes sensitive characters who, drifting in the Atlantic Ocean, find love, just possible by means of acknowledgement of their own bodies and the Iberian environment.

\section{Keywords}

José Saramago; voyage; identity; memory; fiction; history. 


\section{Sumário}

1. Introdução 10

2. Uma ilha mágica e caminhantes imaginários 14

2.1. A memória literária e as matrizes histórico-narrativas 19

2.2. O cão Fiel, Dois Cavalos e dois cavalos 25

3. A deriva das personagens do romance 32

3.1. As artes de Amor 41

3.2. Mulheres que sabem ao sal 46

4. "Rosto da Europa" 50

4.1. "No Xadrez Mundial Moveu-se uma Pedra" 55

4.2. "O clamor surdo do mar" 62

5. Conclusão 68

6. Referências bibliográficas 71 
Caminante no hay camino

Todo pasa y todo queda, pero lo nuestro es pasar, pasar haciendo caminos caminos sobre el mar.

Antonio Machado 